\title{
Informe de la Comisión Técnica de la A.E.N. sobre la Residencia «San José» de Burgo de Osma (Soria)
}

En virtud de la petición realizada ante la Junta Directiva de la Asociación Española de Neuropsiquiatría para realizar una evaluación de la Residencia "San José" de Burgo de Osma (Soria), los integrantes de la comisión técnica nombrada al efecto realizamos una visita de trabajo al establecimiento el pasado 2 de Agosto de 2000. En el curso de la misma estudiamos las condiciones asistenciales del centro y nos entrevistamos con los responsables políticos y profesionales del mismo. Con los datos obtenidos en dicho momento, ampliados en un encuentro posterior con la Administradora y Terapeuta Ocupacional de la Residencia, de quienes provenía la queja inicial sobre el funcionamiento de la Residencia, se emite el informe que sigue a continuación.

\section{Hechos Objetivos.}

1.- La Residencia "San José" es un heterogéneo centro donde se atiende a ancianos -79 residentes-, a retrasados mentales -53 residentes- y a pacientes psiquiátricos -58 residentes-. Lo insólito de la circunstancia no es tanto la incongruente mezcla cualitativa de residentes cuanto que ésta no proviene de la reforma de un antiguo Hospital Psiquiátrico. No estamos, en este sentido, ante una población residual adcrita a los Servicios Sociales de alguna Administración tras la aplicación de la Reforma Psiquiátrica, sino que el ingreso de personas con patología psíquica se ha realizado, en su mayoría por motivos sociales, al margen de los dispositivos sanitarios de Salud Mental del Área a la que pertenecen.

2.- Pese a la elevada población con patología psíquica existente, la plantilla de personal es muy escasa, llamando la atención la ausencia total de psiquiatras, de ATS/ DUE - salvo las religiosas diplomadas no sometidas a turnos $-\mathrm{y}$ de educadores. Los ciudadores o veladores, por otra parte, no están titulados.

3.- No existe un estudio clínico de los pacientes mentales ni un proyecto rehabilitador de los mismos.

4.- No existen recursos técnicos para hacer frente a posibles alteraciones de conducta salvo el uso de las celdas de aislamiento habilitadas a tal efecto o la restricción de la libertad de salida. Si bien es cierto que en el centro no se respiraba en el momento de la visita un ambiente opresivo, el paternalismo y los buenos sentimientos no pueden suplir los instrumentos técnicos exigibles en el trato especializado con paciente psíquicos, ni pueden evitar abusos comprobados como su empleo a modo de celda de castigo. Lo mismo cabe sostener respecto a la prohibición de las salidas y su posible arbitrariedad. 
INFORMES

5.- La estructura arquitectónica es muy antigua, existiendo aún dormitorios con 10 y hasta con 20 camas. El centro se encuentra actualmente en obras de remodelación.

6.- El internamiento de la mayoría de los pacientes, en tanto que pacientes con trastornos psíquicos, no se atiene a lo dispuesto con ese fin en el Código Civil en su artículo 211. No pueden ser considerados, por lo tanto, residentes en sentido estricto sino personas retenidas ilegalmente.

7.- Se incumplen igualmente los artículos 203 y 229 del citado Código Civil, en tanto que las autoridades responsables de la Residencia no han puesto en conocimiento del Ministerio Fiscal la existencia de posible causa de incapacitación en buen número de residentes. Según se nos ha informado el problema está en vías de resolución y se han realizado recientemente los trámites necesarios.

8.- La Administración de la Residencia ejerce como administrador de los residentes, vulnerado gravemente lo obligado por el Código Civil en materia de tutela y curatela.

9.- La Superiora de la Comunidad ejerce al mismo tiempo como Directora de la Residencia, al parecer según lo establecido en vigente Convenio de la Diputación de Soria con Las Hijas de la Caridad, lo que origina, pese a la presumible capacidad de la persona actualmente elegida, lógica y anacrónicas distorsiones en los órganos directivos de la institución.

\section{Recomendaciones.}

1.- Suspender radicalmente el ingreso de enfermos mentales, que deberán ser siempre remitidos a la red de Salud Mental normalizada en la provincia de Soria.

2.- Proceder a la creación de un equipo multiprofesional, suficientemente amplio, que estudie clínicamente a la población residente con patología psíquica y proponga los programas rehabilitados a realizar a corto, medio y largo plazo.

3.- Establecer contactos con los responsables sanitarios de Salud Mental y de Servicios Sociales de la Comunidad de Castilla y León para estudiar el destino de la población que, tras los estudios y los tratamientos indicados, haya de permanecer internada donde proceda- con carácter residencial.

4.- Proponer convenios para trasladar a centros específicos a los pacientes con retraso mental.

5.- Completar la reforma arquitectónica de la Residencia.

6.- Informar al Ministerio Fiscal, si no se ha hecho ya, de la existencia de presuntos incapaces para que se proceda a regular el internamiento, a tramitar los expedientes de incapacitación que disponga el Juez, y a nombrar los tutores y administradores necesarios cuando corresponda.

7.- Crear un órgano directivo secular y más acorde con los tiempos. 